\title{
EDUCAÇÃO EM SAÚDE NA ESTRATÉGIA SAÚDE DA FAMÍLIA: O SIGNIFICADO E A PRÁXIS DOS ENFERMEIROSa
}

Health education in the family health strategy program: the meaning and praxis of nurse

\author{
Educación en salud en la estrategia salud de la familia: el significado y la praxis de los \\ enfermeros
}

Simone Roecker

Sonia Silva Marcon²

\section{RESUMO}

0 estudo objetivou identificar o significado da educação em saúde para os enfermeiros da Estratégia Saúde da Família (ESF) e as ações educativas individuais e coletivas desenvolvidas por eles. Participaram da pesquisa 20 enfermeiros que atuam na ESF no âmbito da $10^{\text {a }}$ Regional de Saúde do Estado do Paraná. Trata-se de um estudo descritivo-exploratório com abordagem qualitativa. Os dados foram coletados em abril de 2010, por meio de entrevistas semiestruturadas gravadas, e submetidos à análise de conteúdo categorial. Os resultados apontam para duas categorias: desvelamento do significado da educação em saúde sob a ótica dos enfermeiros; e a práxis educativa no cotidiano dos enfermeiros. Conclui-se que há necessidade de se esclarecer os objetivos da ESF relacionados à educação em saúde aos profissionais, e estabelecer um processo de capacitação e educação permanente para que ela seja eficaz e propicie a prevenção de doenças e a promoção da saúde da população.

Palavras-chave: Educação em saúde. Saúde da família. Enfermagem em saúde pública. Atenção primária à saúde.

\begin{abstract}
The study aimed to identify the meaning of health education for the nurses of the Family Health Strategy Program (ESF) and the individual and collective educational actions developed by them. In the research took part 20 nurses who work in the ESF program within the $10^{\text {th }}$ Regional of Health of Paraná State. This is a descriptive-exploratory study with qualitative approach. Data were collected in April 2010 through semi-structured recorded interviews, and submitted to the analysis of its categorical content. Results point to two categories: unveiling of the meaning of health education under the nurses' view; and the educational praxis in the quotidian of the nurses. It is concluded that there is a need of clarifying the objectives of ESF related to health education to the professionals, and to establish a training process and permanent education so that it becomes effective propitiating prevention of diseases and promoting health to the population.
\end{abstract}

keywords: Health Education. Family Health. Public Health Nursing. Primary Health Care.

\section{Resumen}

El estudio tuvo como objetivo identificar el significado de la educación en salud para los enfermeros de la Estrategia Salud de la Familia (ESF) y las acciones educativas individuales y colectivas desarrolladas por ellos. Participaron de la investigación 20 enfermeros que actúan en la ESF en el ámbito de la $10^{\mathrm{a}}$ Regional de Salud del Estado de Paraná. Se trata de un estudio descriptivo y exploratorio con abordaje cualitativo. Los datos fueron recogidos en abril de 2010 a través de entrevistas semiestructuradas grabadas, y sometidos al análisis de contenido de categorías. Los resultados apuntan para dos categorías: desvelamiento del significado de la educación en salud bajo la óptica de los enfermeros; y la praxis educativa en el cotidiano de los enfermeros. Se concluye que hay necesidad de aclararse los objetivos de la ESF relacionados a la educación en salud a los profesionales, y establecer un proceso de capacitación y educación permanente para que ésta sea eficaz y propicie la prevención de enfermedades y la promoción de la salud de la población.

Palabras clave: Educación en Salud. Salud de la Familia. Enfermería en Salud Pública. Atención Primaria de Salud.

${ }^{1}$ Enfermeira. Mestre em Enfermagem. Docente do Curso de Enfermagem da Universidade Estadual do Oeste do Paraná. Cascavel-PR Brasil. Email: moneroecker@hotmail.com; ²Enfermeira. Doutora em Filosofia da Enfermagem. Docente da pós-graduação em Enfermagem da Universidade Estadual de Maringá. Maringá-PR. Brasil. Email: soniasilva.marcon@gmail.com 


\section{INTRODUÇÃO}

O Sistema Único de Saúde (SUS), construído e regulamentado pela Constituição Federal de 1988, tinha e tem como objetivo reduzir a lacuna, ainda existente, entre os direitos sociais garantidos em lei e a capacidade real de oferta dos serviços públicos de saúde à população brasileira. ${ }^{1}$ Entretanto, o modelo assistencial vigente, centrado na doença, apesar de ter passado por diversas críticas ainda permanece hegemônico no processo de atenção à saúde, constituindo-se em desafio para a consolidação do processo de reforma do sistema de saúde no Brasil.

Dessa forma, identificou-se que o modelo de saúde centrado na doença precisava ser revertido, assim o Ministério da Saúde (MS) propôs, em 1994, a implantação do Programa Saúde da Família, hoje denominado Estratégia Saúde da Familia (ESF), considerada um modelo de atenção primária, criada a fim de substituir o modelo de atenção à saúde tradicional. ${ }^{2}$

Com a implantação da ESF, os profissionais de saúde deveriam atuar de modo a contemplar não só o indivíduo e sua doença, mas um cuidado que visa promover à saúde de toda a família e comunidade, principalmente por meio da prevenção. Nesse novo contexto, dentre as atividades desenvolvidas pelos profissionais nas equipes de saúde da família, a educação em saúde ganha imenso destaque. Salienta-se que as ações educativas estão inseridas no trabalho dos profissionais da saúde, principalmente no do enfermeiro, cuja essência é o cuidado, o qual envolve um conjunto de aç̃os, e a educação em saúde é um dos elementos centrais. ${ }^{3}$

No entanto, antes de a educação em saúde se tornar a essência do cuidado na ESF, ela teve um percurso histórico no Brasil; até o início do século XX as preocupações do setor saúde estavam focadas basicamente nas situações de epidemia e, no campo da educação, restringia-se ao ensino de hábitos de higiene e mudança de comportamento, sem considerar qualquer influência dos fenômenos sociais e, muito menos, as origens estruturais, sociais e econômicas dos problemas de saúde. Essa visão começa a se transformar a partir da criação da Organização Mundial da Saúde (OMS) em 1945, na qual ocorre a mudança de nomenclatura, passando a educação sanitária a ser chamada de educação em saúde, que vem se ampliando e incorporando novos objetivos. ${ }^{4-5}$

Acredita-se que a partir das várias abordagens existentes sobre a educação em saúde, esta pode ser definida por meio de dois modelos distintos: o modelo preventivo de educação em saúde, também denominado educação tradicional em saúde, e o modelo de promoção da saúde, também denominado educação radical em saúde. ${ }^{6}$

Portanto, a educação sanitária também denominada modelo tradicional de educação era baseada na concepção de que o indivíduo tinha que aprender a cuidar de sua saúde e que ela era entendida como a ausência de doença. As orientações em saúde eram repassadas seguindo a educação tradicional e a educação "bancária", denominada por Paulo Freire, na qual era enfatizada a transmissão de conhecimentos de forma verticalizada. Entretanto, a educação em saúde também denominada modelo radical de educação, por sua vez, deve se basear na concepção de que o indivíduo aprende a cuidar de sua saúde, e que ela é resultante de múltiplos fatores intervenientes no processo saúde/doença. ${ }^{7}$ A educação em saúde contemporânea (radical) visa preparar o indivíduo para buscar melhores condições de vida, sendo estimulado a tomar decisões e a exercer a autonomia sobre a sua própria vida. ${ }^{6,8}$

Perante a importância do tema exposto e o crescente interesse em conhecer o trabalho educativo na ESF, o estudo objetivou identificar o significado da educação em saúde para os enfermeiros que atuam na ESF e as ações educativas individuais e coletivas desenvolvidas por eles junto à população.

\section{MATERIAL E MÉTODO}

Trata-se de um estudo descritivo-exploratório com abordagem qualitativa, que integra um projeto de pesquisa maior intitulado: "0 trabalho assistencial e educativo no cotidiano do enfermeiro no PSF - características e desafios", apoiado financeiramente pela Fundação Araucária.

0 foco de investigação foi o trabalho educativo em saúde desenvolvido pelos enfermeiros atuantes na ESF em municípios que integram a $10^{a}$ Regional de Saúde (RS) do Paraná, a qual é composta por 25 municípios e que tem como sede o município de Cascavel.

Para efeitos do estudo os municípios que compõe a $10^{\mathrm{a}}$ RS foram divididos em cinco grupos, de acordo com o porte populacional: menos de 5.000 habitantes (seis municípios); de 5.000 a 10.000 habitantes (dez municípios); de 10.000 a 20.000 habitantes (sete municípios); de 20.000 a 35.000 habitantes (um município); e com mais de 35.000 habitantes (um município).

Realizou-se a seleção de oito municípios para o estudo; nos três primeiros grupos em que havia mais de um município foi realizado o sorteio aleatório de dois deles, e nos outros dois grupos, como havia apenas um município, estes foram selecionados. Isso porque, entende-se que ao possuir características populacionais distintas, os municípios também possuem capacidades diferenciadas de atendimento de saúde à população, o que pode determinar a realização do trabalho educativo pelos enfermeiros, além do fato de não termos tempo suficiente para realizar o estudo em todos os municípios da Regional de Saúde.

Todos os enfermeiros atuantes na ESF dos municípios incluídos no estudo poderiam ser informantes, desde que atendessem aos seguintes critérios de inclusão: integrar uma equipe de ESF completa e estar atuando na mesma equipe há pelo menos cinco meses. Esse período foi estabelecido devido ao fato de acreditarmos que é necessário um tempo de atuação do enfermeiro junto à mesma comunidade para que ele, juntamente com a sua equipe, possa conhecê-la, e assim 
conseguir implantar e implementar ações educativas com base nas necessidades da população de sua área de abrangência. Desse modo, do total de 27 enfermeiros atuantes nas equipes de ESF nos municípios selecionados, 20 participaram do estudo, considerando que quatro não atendiam aos critérios de inclusão, um estava de férias, um foi afastado por questões de saúde e outro não aceitou participar do estudo.

A coleta dos dados foi realizada no mês de abril de 2010, por meio de entrevistas semiestruturadas, as quais, após o consentimento dos sujeitos e assinatura do termo de consentimento livre e esclarecido, foram gravadas em equipamento do tipo gravador digital. As entrevistas foram norteadas por um roteiro semiestruturado constituído de duas partes: a primeira, com questões objetivas concernentes ao perfil sociodemográfico dos pesquisados; e a segunda, com questões abertas relacionadas à educação em saúde junto à população. Vale ressaltar que tais entrevistas foram previamente agendadas por telefone, conforme a disponibilidade de cada profissional, das quais 16 ocorreram em sala reservada nas unidades de saúde de atuação de cada profissional, três na secretaria de saúde de Cascavel, em dia de reunião, e um na $10^{a}$ RS em dia de capacitação.

Para análise e interpretação dos dados, utilizou-se a análise de conteúdo; ${ }^{9}$ assim, procedeu-se a pré-análise e exploração dos dados, com sucessivas leituras, seguida da categorização, que consistiu em isolar os elementos do discurso e impor certa organização às mensagens. Após a categorização das falas, procedeu-se, então, a inferência por meio dos dados obtidos e utilizando como base teórica o material disponível em publicações científicas acerca do trabalho educativo na ESF.

0 estudo foi realizado em conformidade com as exigências da Resolução 196/96 do Conselho Nacional de Saúde, com aprovação do projeto pelo Comitê Permanente de Ética em Pesquisa com seres humanos da Universidade Estadual de Maringá sob parecer n659/2009.

Para a diferenciação dos sujeitos e preservação de sua identidade, os informantes foram identificados com a letra ' $E$ ' acompanhada de numeral arábico, o qual indica a ordem em que foram realizadas as entrevistas.

\section{RESULTADOS E DISCUSSÃO}

Inicialmente é descrito o perfil sociodemográfico dos enfermeiros, com a finalidade de conhecer a população em estudo. Em seguida são apresentadas as duas categorias emanadas no decorrer da análise do conteúdo: "Desvelamento do significado da educação em saúde sob a ótica dos enfermeiros", e "A práxis educativa no cotidiano dos enfermeiros".

\section{Caracterização dos Informantes do Estudo}

Dos 20 enfermeiros em estudo, 19 eram do sexo feminino, 12 se encontravam na faixa etária de 22 a 30, e os demais (8) na faixa etária de 31 a 45. Mais da metade (12) eram casados; 6 eram solteiros; 1 , em união consensual; e 1, divorciado.

A maior parte (13) graduou-se em universidades públicas, sendo que o tempo de formação variou bastante; 7 se formaram mais recentemente (entre 1 e 4 anos), 12 estavam formados entre 5 e 10 anos e 1, a 20 anos. Identificou-se que a grande maioria (19) cursou, ou estava cursando, pósgraduação lato sensu. Quanto à área da especialização, observaram-se áreas distintas, com o predomínio da Saúde Pública (12).

0 tempo de atuação na atual Unidade de Saúde da Família (USF) variou de 5 meses a 8 anos. Em relação às condições de trabalho, 17 eram concursados e apenas 3 eram celetistas; 2 destes possuíam mais de um vínculo empregatício. A renda familiar mensal apresentou um predomínio (11) de 6 a 9 salários mínimos e a maioria (17) possuía de 2 a 5 dependentes desta renda.

\section{Desvelamento do Significado da Educação em Saúde sob a Ótica dos Enfermeiros}

A educação em saúde tem se destacado no cenário da atenção primária à saúde sendo parte integrante do trabalho do enfermeiro, e também de sua equipe na ESF. A literatura disponível ${ }^{6-8}$ mostra que as ações educativas são desenvolvidas pelos profissionais seguindo dois moldes diferenciados, ou seja, o modelo tradicional e o radical. Tal fato desperta o interesse em conhecer a percepção dos enfermeiros quanto à educação em saúde, além das atividades que são por eles realizadas. Ao desenvolver esse estudo foi possível identificar a presença dos dois modelos educativos orientando o seu fazer, ou seja, a Educação em Saúde na perspectiva tradicional e a Educação em Saúde na perspectiva radical, que são apresentados detalhadamente a seguir:

\section{Educação em Saúde na Perspectiva Tradicional}

Ao questionar os participantes do estudo sobre 0 significado da educação em saúde, observou-se a presença do modelo tradicional ainda muito arraigado ao conceito dos enfermeiros do estudo:

Educação em saúde eu diria que seriam formas de educar a população para que ela não ficasse doente, seria a prevenção das doenças por meio da educação, das nossas orientações (E17).

São as ações que a gente desenvolve através de palestras, reuniões, orientações junto à população (E5).

Para mim é tentar mudar a cabeça das pessoas por meio da orientação, por que as pessoas ainda têm muito aquela visão do assistencialismo, do curativismo (E16). 
Salienta-se que a educação em saúde não deve se basear apenas nas orientações vinculadas principalmente às doenças, à prevenção dos agravos destas e à identificação de culpados pelo desequilíbrio da saúde ou pela doença, mas sim, buscar conscientizar a população, de modo geral, sobre todos os fatores que estão relacionados e podem ser os possíveis determinantes das enfermidades.

0 trabalho inclui a orientação das pessoas para cuidar de sua saúde quando a doença já está instalada, mas não somente para que ela entenda as causas e as consequências do evento patológico, mas que os profissionais possam despertar nos indivíduos a consciência da importância do cuidado com a saúde, do conhecimento quanto às formas de cuidar de si e do entendimento pleno do processo saúde/doença.

0 modelo educativo tradicional em saúde tem como meta substituir os comportamentos tidos como nocivos à saúde por comportamentos saudáveis, por meio da transmissão de informações, das orientações repassadas às pessoas. É baseado nos pressupostos de que a prevenção é melhor do que a cura, mas que o comportamento individual é o fator-chave da etiologia das doenças. Dessa forma, a educação em saúde tem como objetivo a prescrição de regras para mudar as condutas que causam as doenças. Este enfoque preventivo não considera os fatores psicológicos, espirituais, políticos e sociais que influenciam a conduta ante a doença, e ainda culpam o indivíduo pela sua enfermidade, utilizando práticas impositivas de

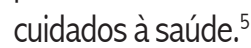

Por isso, não é apenas por meio das orientações, sejam elas individuais ou coletivas, e da tentativa de mudar 0 pensamento das pessoas quanto ao processo saúde/doença, que se consegue atingir o objetivo primordial da ESF, que é promover a saúde dos indivíduos, família e comunidade.

A educação em saúde no modelo tradicional ainda é repleta de ações relacionadas à mudança de pensamento e de comportamento das pessoas, sem se atentar para a influência que os fatores socioeconômicos, espirituais e culturais têm sobre o processo saúde/doença dos indivíduos. Portanto, as ações educativas em saúde precisam ser realizadas com o objetivo de integrar a comunidade nos serviços, demonstrando a ela a importância da sua participação efetiva nas decisões junto à equipe que possa determinar os objetivos e as propostas de trabalho para com a própria comunidade, visando à promoção da saúde. Mas, há que se considerar, atualmente nos serviços de saúde, que a maioria das ações são planejadas pelos coordenadores de equipes e pelos gestores municipais sem que haja a participação dos cidadãos, mesmo tendo claro que as ações serão voltadas ao atendimento exclusivo da população da área de abrangência, ou seja, normalmente as ações são planejadas mediante metas e objetivos da ESF e não conforme as reais necessidades de saúde de determinada população:

Para mim educação em saúde é tudo o que a gente pensa, planeja, organiza no intuito de desenvolver na comunidade, são as orientações que repassamos visando alcançar as nossas metas (E14).

A educação em saúde, em especial na ESF, deve ser uma atividade de grande relevância, tanto para os profissionais quanto para a comunidade, pois os objetivos da ESF só serão alcançados mediante práticas educativas que visem à promoção da saúde dos indivíduos. Para tanto, é necessário que a equipe planeje e organize com participação dos usuários atividades que englobem toda a população nos diversos ciclos de vida.

Pode-se afirmar que a atenção primária em saúde se expandiu e se qualificou por meio da ESF, que compõe parte do conjunto de programas e políticas prioritárias do MS. Portanto, esta estratégia tem o propósito de superar o modelo antigo de caráter unicamente centrado na doença, desenvolvendo-se por meio de práticas gerenciais, democráticas e participativas, sob a forma de trabalho em equipe e integradas com a comunidade, voltadas às populações de territórios demarcados, pelos quais as equipes são responsáveis. ${ }^{2}$

Ressalta-se que no processo de trabalho na saúde da família, é definida como função prioritária de todos os membros da equipe a realização de ações de educação em saúde que visam promover a saúde da população e ao mesmo tempo estimular a participação desta nas decisões sobre o processo saúde/doença a fim de qualificar a assistência à saúde na atenção primária. $^{10}$

\section{Educação em Saúde na Perspectiva Radical}

As práticas educativas no modelo radical de educação em saúde referem-se às atividades voltadas para 0 desenvolvimento de capacidades dos indivíduos e da coletividade, visando à melhoria da qualidade de vida e saúde das pessoas. Percebeu-se nos relatos de alguns enfermeiros que o conceito de educação em saúde é entendido com base no modelo radical:

É você educar a pessoa para que ela possa cuidar da saúde dela, é capacitar, é empoderar para que ela se autocuide (E3).

Educação em saúde eu acho que é você educar a pessoa, estar orientando no sentido de estar promovendo a saúde dela, estar prestando um cuidado que promova a saúde (E11).

Então a educação em saúde seria a comunicação, ou seja, eu comunicar a pessoa, educar para viver bem e para ter saúde (E13).

Por meio dos relatos dos participantes, identificou-se que o trabalho educativo já é realizado conforme preconiza o modelo radical, ou seja, orienta, informa os indivíduos de forma mais flexível, voltada para a promoção da saúde, a melhoria da 
qualidade de vida, a conscientização e o empoderamento, e não apenas enfoca a doença e a culpabilização do indivíduo.

Constata-se que é necessário prestar uma assistência de qualidade aos usuários perante as diversas doenças quando elas já estão instaladas, mas deve ser a base e o objetivo do trabalho das equipes da ESF a educação em saúde, a prestação de um cuidado baseado na informação, na conscientização da população sobre os seus direitos e responsabilidades quanto às questões que envolvem a sua saúde e as condições de vida. Desse modo, atuar na ESF de modo a desenvolver nas pessoas um senso crítico sobre a sua realidade e a ampliação do controle social dos indivíduos é o que valoriza as ações dessa estratégia e amplia as chances de desenvolvimento de uma política de saúde integrativa, democrática e resolutiva.

Nessa direção, o modelo educativo radical está baseado no princípio de que o usuário, a partir da compreensão das informações fornecidas pelos serviços de saúde, faça livremente as suas escolhas. Ao profissional cabe, portanto, conhecer a forma de cuidado, as crenças e valores dos usuários, e a partir destas planejar as suas ações. E na avaliação da efetividade do aspecto educativo é considerado o grau de entendimento que 0 usuário tem da situação, e não somente a mudança de comportamento, pois este enfoque busca as origens dos problemas de saúde nos fatores sociais, econômicos e políticos e a sua meta é gerar consciência pública dos indivíduos sobre os interesses, principalmente de ordem econômica, que interferem nas condições de saúde da população. ${ }^{5}$

Ademais, percebe-se que a educação em saúde vem sendo repensada ao longo dos anos, no sentido de modificar as ações educativas persuasivas, com transferência verticalizada de informações, negação da subjetividade do ser que recebe as orientações e autoridade do educador para ações que possam desenvolver a autonomia e o empowerment (entendido como ampliação de poder, empoderamento ou fortalecimento e participação comunitária) dos sujeitos. ${ }^{11}$

Destaca-se que o processo educativo realizado pelos enfermeiros na ESF, além de desenvolver a autonomia individual sobre o controle da sua saúde, deveria também atuar no intuito de despertar o empoderamento, a interação de toda a comunidade na realidade dos serviços de saúde; diante disso, observou-se que para alguns participantes isso fica evidente:

Educação em saúde pra mim é o ato de educar, de orientar e de transmitir informações para as pessoas para que elas possam cuidar da sua saúde e também da saúde da comunidade (E10).

Para mim, educação em saúde é o que a gente orienta para o usuário, o que seria de bem comum. Seria a gente enquanto profissional difundir 0 conhecimento que temos e que pode fazer a diferença na vida e na saúde dessa pessoa, então é uma forma de estar orientando para uma melhor qualidade de vida de toda a comunidade (E15).

Entende-se que na ESF o foco primordial da atenção à saúde deve ser a realização de ações, principalmente de cunho educativo, junto aos indivíduos em sua totalidade, sem distinção de crenças, cultura, grau de escolaridade, ou situação econômica e social, buscando sempre despertar nas pessoas o interesse pelo conhecimento das diversas formas de obter adequadas condições de saúde e de exercer a plena cidadania.

Desse modo, a educação em saúde deve estar presente em todas as ações para promover a saúde e prevenir as doenças, facilitando a incorporação de ideias e práticas corretas que passem a fazer parte do dia-a-dia dos indivíduos, de forma a atender suas reais necessidades. Tomando como ponto de partida o saber produzido em todas as situações vivenciadas no cotidiano com a comunidade, deve-se procurar atender aos interesses dos vários grupos sociais pertencentes às distintas classes sociais.? $^{\text {? }}$

Assim, a educação em saúde realizada pelo enfermeiro da ESF deve propiciar nos indivíduos uma reflexão crítica, problematizadora, ética, estimulando a curiosidade, o diálogo, a escuta e a construção do conhecimento compartilhado. ${ }^{12}$

\section{A Práxis Educativa no Cotidiano dos Enfermeiros}

Ao identificar que os enfermeiros compreendem 0 conceito de educação em saúde, de formas distintas e com base nos dois modelos abordados nesse estudo, busca-se conhecer as ações educativas que são realizadas junto à população na ESF.

A seguir estão apresentados os dados conforme a realização do trabalho educativo relatado pelos enfermeiros, sendo agrupados em atividades educativas individuais e coletivas.

\section{Atividades Educativas}

Pelo fato de a educação em saúde ser a base das ações desempenhadas pelos profissionais na ESF, além de ser o principal meio de se prevenir e, consequentemente, promover a saúde da população, observou-se nos relatos de alguns participantes que essas ações ainda são realizadas minimamente:

Realizo pouca educação em saúde, mas as principais atividades são individuais [...] (E7)

Desenvolvo muito pouco a educação em saúde, mas às vezes faço $\operatorname{sim}[. .$.$] (E9).$

Percebe-se que a realização, ou não, destas atividades está intimamente inter-relacionada ao perfil desse profissional, aos seus objetivos de trabalho e, principalmente, ao seu comprometimento com os princípios fundamentais da ESF: 
Desenvolvo atividade educativa todo dia, toda hora (E13).

Na verdade, a educação em saúde é constante, sempre que a gente aborda um paciente acaba fazendo orientações (E14).

0 desenvolvimento das atividades educativas depende muito do interesse e empenho dos profissionais que atuam na ESF. Sabe-se que existem muitos fatores que podem interferir na execução destas atividades, como, por exemplo, a sobrecarga de trabalho dos enfermeiros, a gerência e coordenação da USF, as reuniões, a escassez de recursos materiais e humanos, entre outros, mas que esses não devem se constituir em barreiras para a efetivação do trabalho educativo em saúde.

Contudo, não são apenas estes os motivos da não realização da educação em saúde. Estudo realizado no interior nordestino apontou a desarticulação dos conhecimentos dos membros da equipe de saúde sobre os princípios teóricos, metodológicos e filosóficos da ESF como um dos determinantes do pouco envolvimento do trabalho da equipe com a área educativa, resultando em falta de integração/articulação das ações práticas de uma equipe de ESF com a dimensão educativa. ${ }^{13}$

\section{Atividades no Âmbito Individual}

Todos os participantes do estudo relataram desenvolver atividades educativas em saúde rotineiramente, mas nem todos com a mesma frequência. Dessa forma, observou-se que há prevalência das ações que são vinculadas a programas e políticas do MS, ou seja, voltadas às aç̃̃es que são exigidas e que já estão instituídas.

As ações de educação em saúde que são desempenhadas no âmbito individual estão acompanhadas do número de enfermeiros que as mencionaram em seus relatos, salientando que as ações estão quase em sua totalidade aliadas a outras atividades, sendo normalmente desenvolvidas mediante cronograma diário ou semanal: na puericultura (15), na coleta de exame preventivo (12), no atendimento baseado na queixa e quando o paciente procura a unidade por dúvidas ou para a busca de medicamentos (14), na consulta de enfermagem (9), na visita domiciliária (8), na assistência prénatal (6) e na realização de procedimentos (p. ex., vacinação, verificação de sinais vitais) (4):

Individual eu considero a consulta de enfermagem, orientações que às vezes você dá pra paciente quando não é uma consulta, em um atendimento, quando tem alguma situação, na vacina, na hora que você verifica uma pressão e está alta, no momento que tiver uma oportunidade (E3).
Individual seria mais o preventivo, onde realizo orientações às mulheres [...], e também na puericultura onde faço orientações às mães, e ainda todas as pessoas que eu atendo individualmente eu procuro fazer uma orientação (E4).

Eu acho que durante a consulta de enfermagem [...], lá na puericultura quando oriento as mães, nas visitas domiciliares e quando há a necessidade na unidade com usuários que procuram a unidade por diversos motivos(E11).

Pontua-se que a educação em saúde, mesmo sendo o foco principal da ESF, ainda deixa muito a desejar, ou seja, é realizada apenas no momento em que são efetuados outros atendimentos de saúde principalmente voltados à doença, e que não seria somente este o objetivo do trabalho educativo.

Destarte, a construção do conhecimento com base nas reflexões da práxis de educação em saúde aponta para a necessidade de se concretizar um processo educativo em saúde, envolvendo a comunidade por meio de um processo de interação participativa que seja capaz de permitir uma reflexão crítica da realidade e dos fatores que determinam a qualidade de vida e um viver saudável. ${ }^{14}$

\section{Atividades no Âmbito Coletivo}

No âmbito coletivo foram elencadas as atividades educativas, seguidas pelo número de enfermeiros que as mencionaram nas entrevistas: grupo de HIPERDIA (20), grupo de gestantes (13), nas orientações em sala de espera (5), grupo antitabagismo (3), grupo de planejamento familiar (3), grupo da bolsa-família e pesagem do leite das crianças (3), orientações em escolas (drogas, sexualidade, saúde bucal, higiene corporal e do ambiente) (3), grupo da melhor idade (1), grupo de prevenção à saúde (1), participação em grupo da terceira idade da ação social (1), grupo de saúde mental (1), grupo de saúde da mulher (1), grupo com a comunidade no interior e nos assentamentos (Movimento de Libertação dos Sem-Terra/MLST) para todas as faixas etárias (1), grupo de adolescentes juntamente com o pró-jovem (lixo e reciclagem) (1), projeto de cultivo e uso correto de plantas medicinais em parceria com uma faculdade privada para toda a comunidade (1) e "chamadas" (em que é convocada cada comunidade em dia específico para divulgar informações específicas) (1).

No que concerne às atividades educativas coletivas, visualiza-se que a totalidade delas é desenvolvida por meio de palestras, em que dificilmente há uma interação entre os usuários e os profissionais que exercem o papel de disseminador das informações, e que normalmente são as atividades normatizadas pelo MS, sendo realizadas quinzenal, mensal ou esporadicamente durante 0 ano: 
Temos o grupo de hipertensos e diabéticos (HIPERDIA), grupo de gestantes e o grupo do tabagismo, onde passo informações e realizo palestras (E6)

[...] e ainda temos o grupo de saúde mental, o grupo do bolsa-família e pesagem do leite das crianças que eu acompanho também e o pessoal que recebe o benefício (E3)

- Eu acho que palestras são as atividades que a gente faz com a população; nós temos o grupo de hipertensos e diabéticos, saúde da mulher em pequenos grupos, com os adolescentes, nas escolas também, e o grupo de tabagismo, e grupo de gestantes (E8).

Eu faço orientações em sala de espera, HIPERDIA, planejamento familiar, e aqui também a gente trabalha por meio de chamadas, onde a gente chama comunidade por comunidade para abordar temas específicos quando há necessidade [...] (E20).

Destaca-se que, mesmo a ESF sendo um modelo assistencial cujas atividades deveriam estar voltadas para 0 atendimento à família e à comunidade, no intuito de desenvolver nelas a consciência crítica, a participação efetiva nas decisões dos serviços de saúde, no controle social e no empoderamento ainda se debruça sobre os preceitos do modelo biomédico, que são voltados à intervenção no momento da doença. Esse fato é explicitado nos relatos, em que a realização das atividades educativas ocorre por meio de palestras e orientações vinculadas geralmente ao processo da doença já instalada, como é o caso do programa para hipertensos e diabéticos, do grupo para tabagistas, do grupo de saúde mental e, muitas vezes, das atividades em sala de espera que ocorrem normalmente quando há alguma epidemia ou grande número de casos, não somente no momento das doenças, mas também no instante em que a população procura a unidade em busca da assistência, como é o caso da gestação, do acompanhamento das crianças para o recebimento de benefícios do governo e também nas escolas, geralmente quando há disseminação de uma doença.

Nesse contexto, identifica-se que as ações desenvolvidas pelos profissionais na ESF se confrontam com 0 que é preconizado pela estratégia, ou seja, as ações estão ainda voltadas ao modelo biomédico, centrado na doença. Isso pode ser percebido em grande parte nas falas dos participantes quanto ao conceito de educação em saúde, no qual se visualiza que este ainda é influenciado e determinado pelo modelo tradicional de educação em saúde.

Constata-se na literatura ${ }^{15,16}$ que a maioria dos enfermeiros afirmam realizar atividades como palestras e reuniões de grupo junto aos usuários e que a essência das atividades educativas se assemelha ao antigo modelo assistencial de saúde. Enquanto isso, as ações educativas deveriam estar vinculadas à realidade da família atendida e a educação deveria ser vislumbrada como ferramenta que pode contribuir para a reorganização dos serviços de saúde. ${ }^{15}$

No cenário da saúde atual, nota-se, empiricamente, que a prática educativa está centrada nas pessoas doentes ou naquelas suscetíveis a alterações no seu estado de saúde, uma vez que o profissional direciona suas ações para indivíduos que procuram os serviços de saúde devido à possibilidade da existência de alguma doença. ${ }^{16}$

Dentre as atividades coletivas realizadas com frequência pelos enfermeiros, os relatos mostram que os enfermeiros e suas equipes realizam também atividades esporádicas durante o ano:

É feito sim, quando a RS exige, em dias específicos, como o dia internacional da saúde e dias de combates às doenças em geral. Normalmente é feita então uma barraquinha na rua e são realizadas atividades educativas, em que o enfermeiro, os técnicos, os agentes comunitários de saúde (ACS) fazem orientações, mas somente quando a $R S$ cobra (E9).

Ah eu faço esporadicamente quando a gente é convidado, nas creches, orientações [...] para os pais e professores. E faço também orientações no curso de noivos. E quando a $R S$ solicita, e ainda nas datas especificas de combate a determinadas doenças, [...] e isso a gente faz mais em sala de espera mesmo (E11).

Nota-se que a maior parte das atividades realizadas provém das normativas estabelecidas pelo MS, as quais são normalmente exigidas pelas $\mathrm{RS}$, em que se identifica que pouco se faz com base nas reais necessidades da população que são passíveis de observação constante na ESF.

Nessa perspectiva, sendo a ESF um "lócus" de participação da população, deve-se promover uma nova relação entre os sujeitos, em que tanto o profissional quanto o usuário podem ser produtores de conhecimento e da própria saúde. Mas este envolvimento só se torna possível mediante um processo de diálogo entre os saberes técnico-científicos e populares, acreditando-se que o desenvolvimento efetivo dessa participação parte de práticas vivenciadas no cotidiano. Portanto, remodelar a assistência à saúde implica modificar o processo de trabalho, pois a sua implantação por si só não garante que o modelo assistencial esteja sendo alterado, mas com certeza já nos leva a refletir sobre mudanças necessárias e urgentes na forma de agir e implementar ações e serviços no contexto da ESF. ${ }^{17}$

Diante do exposto, observa-se que na prática a ESF é um espaço de reconstrução do processo saúde/doença; contudo, 
ainda é preciso desmitificar conceitos e valores que enfatizam a prevenção e a cura de doenças. Dessa forma, é necessário que toda a equipe atuante nesta estratégia reformule a sua maneira de intervir junto à população, tendo em vista a reconstrução das representações sociais do processo saúde/ doença desta, na perspectiva de um sistema de saúde em defesa da vida. ${ }^{18}$

\section{CONCLUSÃO}

A partir da realização desse estudo, evidenciou-se que os enfermeiros atuantes na ESF no âmbito da $10^{\mathrm{a}} \mathrm{RS}$ conhecem o significado da educação em saúde, mas o trabalho educativo desenvolvido ainda está aquém do preconizado para esse modelo assistencial de prestação de cuidados à saúde da família e comunidade. A realização desse estudo, no entanto, possibilitou conhecer um pouco mais do trabalho educativo dos enfermeiros, e é com base nesse conhecimento, acumulado a partir dos relatos, que se busca adequar e melhorar as ações educativas desenvolvidas junto à população, respeitando seu contexto social, político, cultural e espiritual.

Salienta-se que as atividades individuais realizadas estão geralmente atreladas aos procedimentos e atendimentos do cotidiano, em que não se designa um espaço exclusivo para a educação em saúde. Quanto às atividades desenvolvidas no âmbito coletivo, verifica-se que estas são quase, em sua totalidade, realizadas segundo as normatizações do MS e as exigências da RS, ou seja, as ações tanto individuais como coletivas ainda são desenvolvidas em proporção inferior ao esperado nesta estratégia de trabalho.

Nessa dimensão, pode-se dizer que os pressupostos da ESF estão sendo em parte desenvolvidos pelos profissionais que atuam nas USFs pesquisadas e que essa realidade nos leva a crer que é preciso haver diversas mudanças, como, por exemplo: o despertar do interesse pelo trabalho educativo nos profissionais; maior comprometimento destes com o trabalho; reconhecimento e enfrentamento dos problemas relativos à educação em saúde pelos profissionais, buscando enxergá-los a fim de não utilizá-los como forma de proteção para sua não realização, para que possa ocorrer a real consolidação da inversão do modelo assistencial vigente nesses municípios.

Ainda, nota-se que no cotidiano do trabalho educativo dos profissionais de saúde da ESF há uma sobreposição das ações vinculadas ao modelo tradicional de educação em saúde em relação ao radical, fato este que provavelmente esteja intimamente relacionado com a complexidade do novo modelo e as dificuldades e barreiras que precisam ser perpassadas para se colocar em prática os seus objetivos inovadores.

Notadamente, a educação em saúde na ESF ainda ocorre permeada de contradições, e, para compreendê-la, o profissional de saúde, especialmente o enfermeiro, precisa considerar as novas formas de relações sociais e as necessidades de saúde da população, com vistas a superar as práticas limitadas ao ensinamento de comportamentos saudáveis. É preciso despertar nos profissionais o interesse pela educação em saúde mais efetiva e resolutiva, por meio da integração destas ações com a comunidade.

Conclui-se que há a necessidade de se desenvolver meios que esclareçam os propósitos da ESF, que estabeleçam programas de capacitação destes profissionais ao adentrarem nesta modalidade de trabalho e que esta seja contínua durante todo o período de atuação desses profissionais, propiciando assim o pleno desenvolvimento da educação em saúde e, consequentemente, a promoção da saúde das pessoas.

A partir deste estudo, espera-se contribuir no campo de atuação na ESF, incentivando os profissionais de saúde, em particular o enfermeiro, a desenvolver trabalhos educativos diferenciados, ou seja, focados nas necessidades da população e em parceria com esta, transformando as ações em práticas concisas, eficazes e eficientes, capazes de contribuir com a promoção da saúde. No ensino e pesquisa, espera-se contribuir com a produção científica da área, fornecendo, assim, subsídios para pesquisas futuras sobre a temática em questão.

\section{REFERÊNCIAS}

1.Souza MF. A enfermagem reconstruindo sua prática: mais que uma conquista no PSF. Rev Bras Enferm. 2000 dez; 53(n. esp.): 25-33.

2. Ministério da Saúde (BR). Programa Saúde da Família [periódico online]. 2007; [citado 2009 jan 28]. Disponível em: http:// portal.saude.gov.br/saude/

3. Budó MLD, Saupe R. Conhecimentos populares e educação em saúde na formação do enfermeiro. Rev Bras Enferm. 2004 mar/abr; 57(2): 16569.

4. Westphal MF, Bógus CM, Mendes R, Akerman M, Lemos M do S. La Promoción de Salud en Brasil. In: Arroyo HV, editor. La promoción de la salud en América Latina: modelos, estructuras y vision crítica. San Juan : Universidad de Puerto Rico; 2004. p. 123-54.

5.Bechtlufft LS, Acioli S. Produção científica dos enfermeiros sobre educação em saúde. Rev APS. 2009 out/dez; 12(4): 478-86.

6. Oliveira DL. A 'nova’ saúde pública e a promoção da saúde via educação: entre a tradição e a inovação. Rev Latino-am Enfermagem. 2005 maio/ jun; 13(3): 423-31.

7Pelicioni MCF, Pelicioni AF. Educação e promoção da saúde: uma retrospectiva histórica. 0 Mundo da Saude. 2007; 31(3): 320-28. 
8. Alves VS. Um modelo de educação em saúde para o Programa Saúde da Família: pela integralidade da atenção e reorientação do modelo assistencial. Interface: comunicaçao, saude, educaçao. 2004 set; 2005 fev; 2005; 9(16): 39-52.

9. Bardin L. Análise de conteúdo. Lisboa: Ed 70; 2008.

10.Silva CP, Dias MSA, Rodrigues AB. Práxis educativa em saúde dos enfermeiros da Estratégia Saúde da Família. Cienc Saude Colet. 2009; 14(supl 1): 1453-62.

11.Fracolli LA. Programa Saúde da Família como uma estratégia para inclusão social na perspectiva do trabalho de enfermagem. 0 Mundo da Saúde . 2005 jan/mar; 29(1): 35-40.

12.Guimarães GL. 0 perfil do enfermeiro-educador para o ensino de graduação. Esc Anna Nery. 2005 ago; 9(2): 255-60.

13.Silva CC, Silva ATMC, Losing A. A integração e articulação entre as ações de saúde e de educação no programa de saúde da família û psf. Rev Eletr Enferm. 2006; 8(1): 70-4.

14.Machado MFAS, Monteiro EMLM, Queiroz DT, Vieira NFC, Barroso MGT. Integralidade, formação de saúde, educação em saúde e as propostas do SUS - uma revisão conceitual. Cienc Saude Colet. 2007; 12(2): 335-42.

15Bezerra ALQ, Barbosa MA, Carrijo CIS, Pontes DO, Carmagnani MIS. 0 papel educador do enfermeiro no Programa de Saúde da Família. Rev Paul Enferm. 2004 jan/mar; 23(1): 22-8.

16.Souza LM, Wegner W, Gorini MIPC. Educação em saúde: uma estratégia de cuidado ao cuidador leigo. Rev Latino-am Enfermagem. 2007 mar/ abr; 15(2): 167-74.

17.Costa GD, Cotta RMM, Ferreira MLSM, Reis JR, Franceschini SCC. Saúde da família: desafios no processo de reorientação do modelo assistencial. Rev Bras Enferm. 2009 jan/fev; 62(1): 113-18.

18.Gomes LOS, Aguiar MGG. Programa de Saúde da Família: um espaço para a reconstrução das representações sociais do processo saúde/ doença? Rev Bras Enferm. 2006 set/out; 59(5): 614-19.

\section{NOTA}

a Artigo originado de disser tação de mestrado da primeira autora intitulada: 0 Trabalho Educativo do Enfermeiro na Estratégia Saúde da Família no âmbito da $10^{a}$ Regional de Saúde do Paraná. 2010. Universidade Estadual de Maringá/PR. 